\title{
On-Line Photoinduced Fluorescence for Carbamazepine Determination after Multivariate Optimization
}

\author{
Cecilia Henestrosa ${ }^{1}$, Cecilia Peralta ${ }^{1,2}$, Leslie Aragón³ ${ }^{3}$ Liliana Fernández ${ }^{2,4}$, Gimena Acosta $^{2,3 *}$ \\ ${ }^{1}$ Área de Farmacotecnia, Ética y Legislación Farmacéutica, San Luis, Argentina \\ ${ }^{2}$ Instituto de Química de San Luis (INQUISAL-CONICET), San Luis, Argentina \\ ${ }^{3}$ Área de Gestión en Calidad y Salud, San Luis, Argentina \\ ${ }^{4}$ Área de Química Analítica, Facultad de Química, Bioquímica y Farmacia, Universidad Nacional de San Luis, \\ Chacabuco y Pedernera, San Luis, Argentina \\ Email: *ga costa@unsl.edu.ar
}

How to cite this paper: Henestrosa, C., Peralta, C., Aragón, L., Fernández, 1. and Acosta, G. (2019) On-Line Photoinduced Fluorescence for Carbamazepine Determination after Multivariate Optimization. American Journal of Analytical Chemistry, 10, 513-527.

https://doi.org/10.4236/ajac.2019.1011037

Received: September 16, 2019

Accepted: November 1, 2019

Published: November 4, 2019

Copyright $\odot 2019$ by author(s) and Scientific Research Publishing Inc. This work is licensed under the Creative Commons Attribution-NonCommercial International License (CC BY-NC 4.0). http://creativecommons.org/licenses/by-nc/4.0/ (c) (i) \& Open Access

\begin{abstract}
This work presents a simple and sensitive flow injection fluorimetric method for the determination of carbamazepine (CBZ) in pharmaceutical samples. It is based on the fluorescence signal measurement of the product generated by photoinduced $\left(\lambda_{\mathrm{ex}}=251 \mathrm{~nm} ; \lambda_{\mathrm{em}}=434 \mathrm{~nm}\right)$ using a flow injection manifold containing an on-line homemade photoreactor. In order to optimize the experimental setup, the variable conditions were studied using a multivariate optimization method, thus finding the set of optimum parameters according to the evaluated responses (sensitivity and sampling frequency) and minimizing the number of experiments performed. Under optimal experimental conditions, linear relationship with good correlation coefficient (0.9956) was found between the fluorescence intensity and CBZ concentration in the range of $0.13-40 \mu \mathrm{g} \cdot \mathrm{mL}^{-1}$. The limit of detection was $0.04 \mu \mathrm{g} \cdot \mathrm{mL}^{-1}$. The precision of the method was satisfactory; the values of relative standard deviations were better than $4.36 \%$. The proposed method was validated and successfully applied to the determination of CBZ in pharmaceuticals with good accuracy; being the recovery values from $89.45 \%-112.20 \%$.
\end{abstract}

\section{Keywords}

Online Photoinduced Fluorescence; Multivariate Optimization, Carbamazepine, Pharmaceutical Samples

\section{Introduction}

Carbamazepine (CBZ), 5H-dibenzo[ $b, f]$ azepine-5-carboxamide (Figure 1), is an 


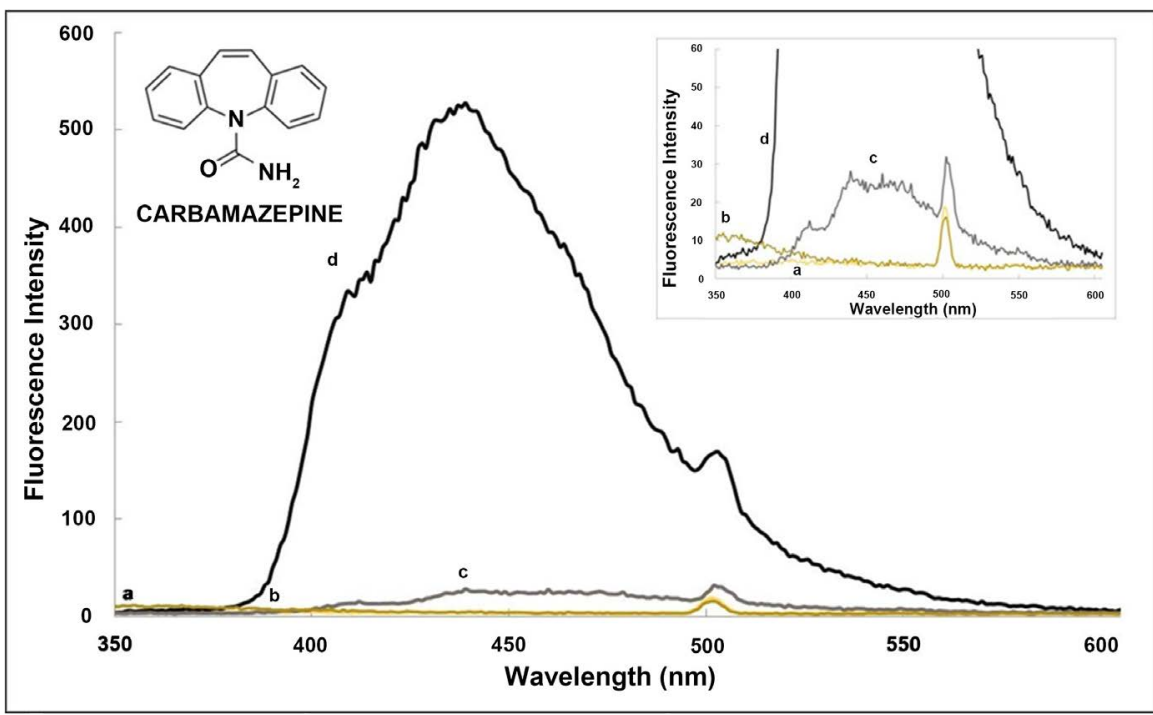

Figure 1. Chemical structure and emission spectra of CBZ: (a) CBZ aqueous solution (5.0 $\left.\mu \mathrm{g} \cdot \mathrm{mL}^{-1}\right)$ without irradiation; (b) $\mathrm{CBZ}$ aqueous solution $\left(5.0 \mu \mathrm{g} \cdot \mathrm{mL}^{-1}\right)+\mathrm{NaOH} 0.1 \mathrm{M}$ without irradiation; (c) solution a irradiated and (d) solution b irradiated.

anticonvulsant and mood-stabilizing drug used primarily in epilepsy treatment and bipolar disorder, as well as trigeminal neuralgia in old age patients [1]. It is also used for a variety of indications, including attention-deficit hyperactivity disorder, schizophrenia, phantom limb syndrome, paroxysmal extreme pain and post-traumatic stress disorders [2] [3]. CBZ is a first-choice anticonvulsant because of its relatively low psychological toxicity and the rarity of serious adverse effects [4].

Several analytical methods have been applied to CBZ determination or its photodegradation products in different matrices; i.e. chromatographic, spectrophotometric, electrochemical and capillary electrophoresis methods [5] [6] [7] [8]. CBZ is not fluorescent in solution but can be converted into a fluorescent compound using UV irradiation, thus fluorimetric methods have been developed in a Nylon surface or through the formation of fluorescent derivatives by transformation assisted with different oxidant agents [9]-[13].

Flow injection analysis (FIA) systems are recognized as excellent automated methods since they show advantages in terms of precision along with significant reduction in reagents and samples consumption, thus minimizing wastes and sampling times; unlike conventional batch mode. Furthermore, FIA schemes are easy to couple with different optical detectors [14] [15].

Optimization of the experimental conditions of an FIA system using the "one variable at a time" methodology require various experiments to modify each factor versus the response studied disregarding the influence that each variable may exert on another and even then, the optimum may not be achieved. The multivariate statistical technique has arisen as an important tool for optimizing analytical processes. One of the most important within them is the response surface methodology (RSM). This method involves various statistical and ma- 
thematical techniques based on fitting a polynomial equation and symmetric models to the experimental data to describe the behavior of the independent variables. The central composite design (CCD) matrix is a type of RSM characterized by an embedded factorial or fractional factorial design with center points that is augmented with a group of "star points" that allow estimation of curvature. If the distance from the center of the design space to a factorial point is \pm 1 unit for each factor, the distance from the center of the design space to a star point is $|\alpha|>1$. The precise value of $\alpha$ depends on certain properties desired for the design and on the number of factors involved [16] [17] [18].

The aim of the present work was to develop a method for CBZ determination using photoinduced fluorescence which is based on the photochemical transformation by UV irradiation. In order to make the proposed methodology suitable for the pharmaceutical analysis, experimental parameters affecting the sensitivity and sampling frequency were studied and optimized by a multivariate experimental scheme. The results were compared with those given by the official methods.

\section{Experimental}

\subsection{Instrumentation and Software}

A Shimadzu spectrofluorometer model RF-5301PC (Kyoto, Japan), equipped with a Xenon discharge lamp was used for the fluorescent measurements and a $120 \mu \mathrm{L}$ volume flow-cell unit for the continuous measurements were used to record transient signals. The CBZ fluorescence measurements were carried out operating the spectrofluorometer in the time-course mode (transient signals; $\lambda_{\mathrm{ex}}$ $=251 \mathrm{~nm} ; \lambda_{\mathrm{em}}=434 \mathrm{~nm}$, slits widths $=3 / 3 \mathrm{~nm}$ ). In batch studies, quartz cells with an optical path length of $1 \mathrm{~cm}$ were used.

The propulsion system consisted of two peristaltic pumps (Gilson Minipuls 3) with Polytetrafluoroethylene (PTFE) tubing. A Rheodyne model 5041 six-port two-way rotary valve (Rohnert Park, CA) was employed.

A home-made continuous photochemical reactor was made as follows: a UV-C source that emits radiation of 100 to $280 \mathrm{~nm}$ was used. The lamp (15 W high pressure Hg, PHILIPS) ignited with a suitable starter and chock, and was surrounded by a $2.5 \mathrm{~m}$ PTFE tubing (internal diameter $=0.75 \mathrm{~mm}$ and outer diameter $=1.0 \mathrm{~mm}$ ), and covered by an aluminum foil, to permit the maximum reflectance of UV light.

In order to minimize interferences by matrix effect, a mini-column $(\mathrm{mC})$ of multiwalled carbon nanotubes (MWCNTs) as adsorbent material was used. It was previously activated following the procedure described by Acosta et al. [19].

A combined glass electrode and a $\mathrm{pH}$ meter Orion Expandable Ion Analyzer (Orion Research, Cambridge, MA, USA, Model EA940) was used for $\mathrm{pH}$ adjustments.

In order to validate the methodology, a chromatographic analysis was performed using an HPLC system equipped with a Gilson 322 pump controller, a 
Rheodyne injector with $20 \mu \mathrm{L}$ loop, a Gilson $170 \mathrm{UV}$-vis diode array detector (Buenos Aires, Argentina). The separative column used was a Phenomenex Luna $5 \mu \mathrm{CN}(250 \times 4.6 \mathrm{~mm})$ (Buenos Aires, Argentina). The mobile phase used was a mixture (85:12:3) of water (milli Q): methanol (Sintorgan Bs. As., Argentina): tetrahydrofuran (JB Baker, New Jersey, USA), to which $0.22 \mathrm{~mL}$ of formic acid (Anedra, Buenos Aires, Argentina) and $0.5 \mathrm{~mL}$ of triethylamine (Merck, Darmstadt, Germany) were subsequently added.

The Stat-Ease Design-Expert Trial Version 11.0 was used for design and analysis of experimental runs. The predicted and adjusted $\mathrm{R}^{2}$ coefficient values were the criteria for the quality of the polynomial model equation was determined by an F-test.

\subsection{Materials}

CBZ $\left(\mathrm{C}_{15} \mathrm{H}_{12} \mathrm{~N}_{2} \mathrm{O}\right.$, MW $\left.236.27 \mathrm{~g} \cdot \mathrm{mol}^{-1}\right)$ was supplied by Parafarm Droguería Saporiti S.A.C.I.F.I.A. rev. 07, Bs. As., Argentina. In the optimization study, the pH was adjusted using $1 \mathrm{~mol} \cdot \mathrm{L}^{-1} \cdot \mathrm{NaOH}$ (Mallinckrodt Chemical Works, New York, Los Angeles, St. Louis, USA) and $0.1 \mathrm{~mol} \cdot \mathrm{L}^{-1} \mathrm{HCl}$ (Merck, Darmstadt, Germany) solutions until the desired $\mathrm{pH}$ value. Multiwalled carbon nanotubes (MWCNTs) $($ diam $=110-170 \mathrm{~nm}$, length $=5.9$ micron, $90+\%)$ were purchased from Sigma Chemical Co. (St. Louis, MO, USA). All other reagents employed in this study were of analytical grade.

\subsection{Stock Solutions}

CBZ stock solutions containing $1 \mathrm{mg} \cdot \mathrm{mL}^{-1}$ were weekly prepared by dissolution of suitable amounts of the drug in $50 \% \mathrm{v} / \mathrm{v}$ ethanol water mixture (Merck Darmstadt, Germany). The standard working solutions of $0.1 \mathrm{mg} \cdot \mathrm{mL}^{-1}$ were prepared daily by stepwise dilutions with doubly distilled water.

\subsection{Sample Preparation}

\subsubsection{Syrup}

A syrup sample volume of $0.25 \mathrm{~mL}$ (Tegretol ${ }^{\circledast}$ Novartis S.A., Bs. As., Argentina, batch $\mathrm{H} 5595$, labeled as $2 \%$ ) was transferred to $50 \mathrm{~mL}$ volumetric flask, and diluted with $50 \% \mathrm{v} / \mathrm{v}$ ethanol water mixture to volume. The CBZ final concentration was about $0.1 \mathrm{mg} \cdot \mathrm{mL}^{-1}$. This solution was further diluted with doubly distilled water and was adjusted to $\mathrm{pH} 11$ with $\mathrm{NaOH}\left(1 \mathrm{~mol} \cdot \mathrm{L}^{-1}\right)$ to obtain suitable experimental conditions for CBZ quantification.

\subsubsection{Tablets}

Ten tablets of Tegretol ${ }^{\circledast}$ (Novartis S.A., Bs. As., Argentina, batch 405731) labeled to contain $200 \mathrm{mg} \mathrm{CBZ}$ per tablet, were weighted and finely powdered. A portion of the powder, equivalent to one tablet $(0.29 \mathrm{~g})$, was accurately weighted, dissolved in $100 \mathrm{~mL}$ of $50 \% \mathrm{v} / \mathrm{v}$ ethanol water mixture and filtered to remove insoluble material. The filtered solution was transferred to a $200 \mathrm{~mL}$ volumetric flask and taken to volume with doubly distilled water. The CBZ final concentra- 
tion was about $1 \mathrm{mg} \cdot \mathrm{mL}^{-1}$. This solution was further diluted and was adjusted to $\mathrm{pH} 11$ with $\mathrm{NaOH}\left(1 \mathrm{~mol} \cdot \mathrm{L}^{-1}\right)$ to obtain suitable experimental conditions for $\mathrm{CBZ}$ quantification.

\subsection{General Procedure}

Standard and samples were injected into a flowing buffer stream conformed by $\mathrm{HCl} 0.003 \mathrm{~mol} \cdot \mathrm{L}^{-1}$. The continuous flow diagram is shown in Figure 2. In the "loading" position, the carrier was impulse by the first peristaltic pump (PP) to the fluorescence detector generating the baseline at $\lambda_{\mathrm{em}}=434 \mathrm{~nm}$ and $\lambda_{\mathrm{ex}}=251$; while the second peristaltic pump aspirate the sample plug, which is pushed towards the photoreactor using $\mathrm{NaOH} \mathrm{pH}$ 11.0. Then, when leaving the photoreactor, the sample was collected into the MWCNTs mC located among 1 and 4 positions at the injection valve. In the "injection" position carrier flowed through the $\mathrm{mC}$ and carried the photoproduct to the detector. The second PP is turned off.

\subsection{Multivariate Optimization}

\subsubsection{Screening Phase: Full Factorial Design (FFD)}

Experimental factorial design is a factorial analysis involving $2^{k}$ experiments (with $k=$ number of studied variables). This type of analysis allows defining important variables affecting the analytical response(s), and its possible interactions. Moreover, a good experimental design provides a simple, efficient, and systematic approach to optimize designs for performance, quality, and cost. Consequently, an FFD was built for the evaluation of the main factors affecting the sensitivity and sampling frequency that may be quantified through Equations (1) and (2), respectively:

$$
\operatorname{Sensitivity~}(S)=\frac{\text { peak area }}{\mathrm{CBZ} \text { standard concentration }}
$$

Sampling frequency $(f)=$

$\frac{60 \mathrm{~min} \cdot \mathrm{h}^{-1}}{\text { baseline time after elution }(\mathrm{min})-\text { injection time }(\mathrm{min})+\text { irradiation time }(\mathrm{min})}$

A two-level full factorial design with $2^{(4)}=16$ experiments (Table 1 ) is described here for the variables: A) $\mathrm{NaOH}$ concentration, mol. $\mathrm{L}^{-1}$ (standard/sample carrier concentration); B) Photoreactor flow rate, $\mathrm{mL} \cdot \mathrm{min}^{-1}$; C) $\mathrm{HCl}$ concentration, mol. $\mathrm{L}^{-1}$ (eluent concentration); D) eluent flow rate, $\mathrm{mL} \cdot \mathrm{min}^{-1}$; while sensitivity, cps.L. $\mathrm{mol}^{-1}(S)$ and sampling frequency, samples $\cdot \mathrm{h}^{-1}(f)$ were regarded as the dependent variables. Maximum and minimum levels of the four factors were determined based on preliminary studies. All experiments were performed in random order to minimize the effects of uncontrolled factors that may introduce bias on the measurements.

\subsubsection{Optimization Phase: Central Composite Design (CCD)}

Once influencing factors were established with the factorial analysis, an RSM was used to find the best conditions for Sensitivity and Sampling frequency at 

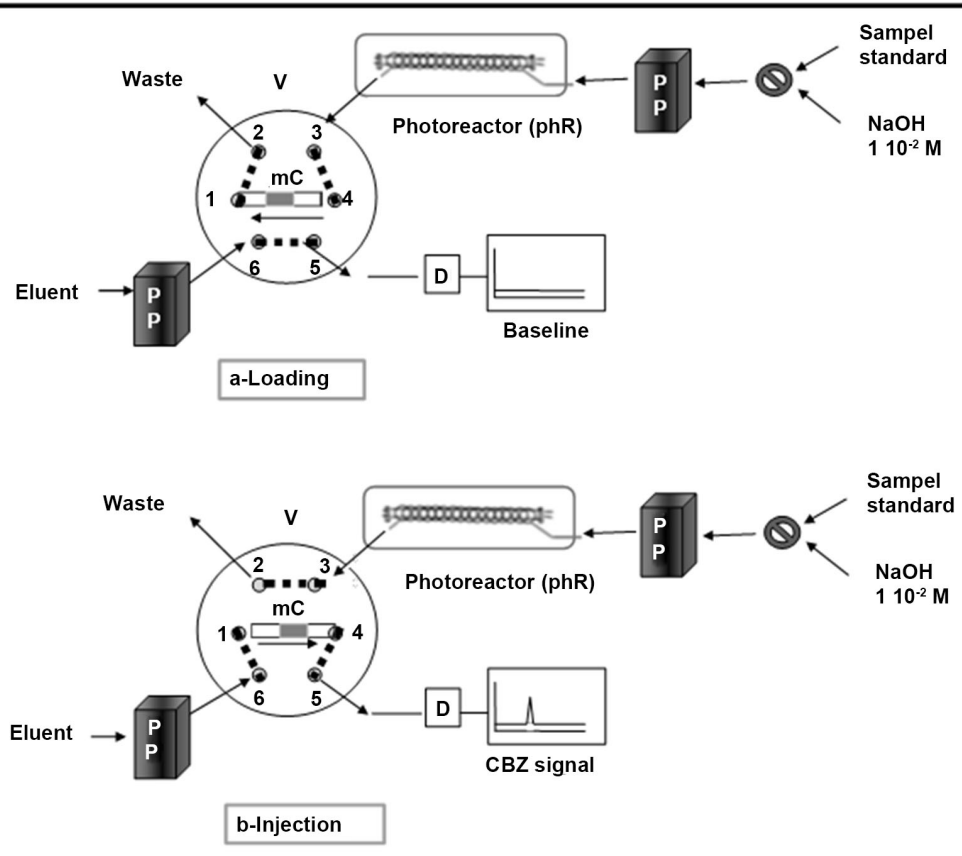

Figure 2. Schematic diagram of the on-line system for CBZ photoinduced determination. PhR: Photoreactor; mC: microcolumn; PP: peristaltic pumps; V: load/injection valve ((a) load position and (b) injection position); (d) spectrofluorimeter detector.

Table 1. Full factorial design (FFD) built for the responses Sensitivity $(S)$ and Sampling frequency $(f)$.

\begin{tabular}{ccccccc}
\hline $\begin{array}{c}\text { Experiment } \\
\text { (run) }\end{array}$ & $\begin{array}{c}\mathrm{NaOH} \text { conc } \\
(\mathrm{A})\end{array}$ & $\begin{array}{c}\text { Photoreactor } \\
\text { flow rate } \\
(\mathrm{B})\end{array}$ & $\begin{array}{c}\mathrm{HCl} \text { conc } \\
(\mathrm{C})\end{array}$ & $\begin{array}{c}\text { Eluent flow } \\
\text { rate }(\mathrm{D})\end{array}$ & $\begin{array}{c}\text { Sampling } \\
\text { frequency } \\
(f)\end{array}$ & $\begin{array}{c}\text { Sensitivity } \\
(S)\end{array}$ \\
\hline 1 & 0.10 & 0.6 & 0.10 & 0.6 & 19 & $6.9 \cdot 10^{6}$ \\
2 & 0.10 & 0.6 & 0.01 & 0.6 & 13 & $9.4 \cdot 10^{5}$ \\
3 & 0.01 & 0.6 & 0.01 & 1.4 & 21 & $8.6 \cdot 10^{5}$ \\
4 & 0.01 & 1.4 & 0.10 & 0.6 & 20 & $2.8 \cdot 10^{5}$ \\
5 & 0.01 & 1.4 & 0.01 & 1.4 & 24 & $1.9 \cdot 10^{5}$ \\
6 & 0.10 & 1.4 & 0.01 & 1.4 & 23 & $4.2 \cdot 10^{5}$ \\
7 & 0.01 & 0.6 & 0.01 & 0.6 & 18 & $1.6 \cdot 10^{6}$ \\
8 & 0.01 & 1.4 & 0.01 & 0.6 & 18 & $1.0 \cdot 10^{6}$ \\
9 & 0.10 & 1.4 & 0.10 & 0.6 & 20 & $9.7 \cdot 10^{5}$ \\
10 & 0.01 & 0.6 & 0.10 & 1.4 & 23 & $5.0 \cdot 10^{5}$ \\
11 & 0.01 & 1.4 & 0.10 & 1.4 & 24 & $1.4 \cdot 10^{5}$ \\
12 & 0.10 & 1.4 & 0.10 & 1.4 & 23 & $3.6 \cdot 10^{5}$ \\
13 & 0.10 & 0.6 & 0.01 & 1.4 & 18 & $4.8 \cdot 10^{6}$ \\
14 & 0.01 & 0.6 & 0.10 & 0.6 & 19 & $1.0 \cdot 10^{6}$ \\
15 & 0.10 & 0.6 & 0.10 & 1.4 & 21 & $2.9 \cdot 10^{6}$ \\
16 & 0.01 & 1.4 & 0.01 & 0.6 & 20 & $2.4 \cdot 10^{5}$ \\
\hline
\end{tabular}


once. A spherical CCD was used here consisting of 27 experiments; i.e. combinations of 4 factorial points, 4 axial points, and replicates of a central point. In the common way, a simple response is analyzed, and the model analysis indicates areas in the design region where the process is likely to give desirable results. To do this, the Derringer's desirability function $(D)$ was used [18]. The desirability approach is a widespread method that gives scores $(\mathrm{Y})$ to a set of responses and chooses factor settings that maximize that score (Equation (3)) with $d_{\mathrm{i}}$, as the individual desirability and $k$ denoting the number of responses.

$$
\operatorname{Desirability}(D)=\frac{d_{1}\left(Y_{1}\right) d_{2}\left(Y_{2}\right) \cdots d_{k}\left(Y_{k}\right)}{k}
$$

The response surface was built with the matrix of data acquired according to a Central composite design that consisted of 27 experiments. Experiments were combinations of the independent variables in the following ranges: $\mathrm{NaOH}$ concentration $0.01-0.1 \mathrm{~mol} \cdot \mathrm{L}^{-1}$; Photoreactor flow rate $0.6-1.4 \mathrm{~mL} \cdot \mathrm{min}^{-1} ; \mathrm{HCl}$ concentration, $0.01-0.1 \mathrm{~mol} \cdot \mathrm{L}^{-1}$; eluent flow-rate, $0.6-1.4 \mathrm{~mL} \cdot \mathrm{min}^{-1}$ (Table 2). The levels studied were selected considering the results of the FFD. Sensitivity and Sampling frequency were thus fitted to polynomial models and the maximum in the experimental domain was then assigned according to the desirability function maximum obtained through simplex optimization. All experiments were performed in random order to minimize the effects of uncontrolled factors that may introduce bias in the measurements.

\subsubsection{Outliers Removed after Cook's Distance Analysis}

Cook's distance, $D i$, is used in regression analysis to find outliers in a set of predictor variables. It is a way to identify points that negatively affect a regression model. The measurement is a combination individual leverage and residual values; the higher the leverage and residuals, the higher the Cook's distance. In this study, the models used as stated in Sections 2.6.1 and 2.6.2 were analyzed by Cook's distance test and outliers were removed.

\section{Results and Discussion}

\subsection{Fluorescence Characteristics of CBZ in Aqueous Medium}

Figure 1 shows CBZ emission spectra and chemical structure of CBZ. Figure 1(a) and Figure 1(b) show the emission spectra of the aqueous and basic solution of CBZ without irradiation. As expected, upon exposure to UV-radiation $\mathrm{CBZ}$ in a basic medium (Figure $1(\mathrm{~d})$ ) was quickly derived to fluorescent compound (photochemical product) with a maximum emission wavelength of 434 $\mathrm{nm}$ when it is excited at $251 \mathrm{~nm}$. This phenomenon was less observed in the irradiated aqueous solution (Figure $1(\mathrm{c})$ ). The fluorescent intensity has been improved 10 times by inducing hydrolysis in basic medium, which would favor the formation of the photoproducts described by Pan et al. [20]. These wavelengths were selected to measure the fluorescence intensity for the following assays. Based on these observations, the optimum medium for the on-line photochemical 
Table 2. Central Composite Design with seven replicates of the central point built for Sensitivity $(S)$ and Sampling frequency $(f)$.

\begin{tabular}{|c|c|c|c|c|c|c|}
\hline $\begin{array}{l}\text { Experiment } \\
\quad \text { (run) }\end{array}$ & $\begin{array}{l}\mathrm{NaOH} \text { conc } \\
\left(\mathrm{mol} \cdot \mathrm{L}^{-1}\right)(\mathrm{A})\end{array}$ & $\begin{array}{l}\text { Photoreactor flow } \\
\text { rate }\left(\mathrm{mL} \cdot \mathrm{min}^{-1}\right)(\mathrm{B})\end{array}$ & $\begin{array}{c}\mathrm{HCl} \text { conc } \\
\left(\mathrm{mol} \cdot \mathrm{L}^{-1}\right)(\mathrm{C})\end{array}$ & $\begin{array}{l}\text { Eluent flow rate } \\
\left(\mathrm{mL} \cdot \mathrm{min}^{-1}\right)(\mathrm{D})\end{array}$ & $\begin{array}{l}\text { Sensitivity } \\
\left(\mathrm{cps} \cdot \mathrm{L} \cdot \mathrm{mol}^{-1}\right)\end{array}$ & $\begin{array}{c}\text { Sampling frequency } \\
\left(\text { samples } \cdot h^{-1}\right)\end{array}$ \\
\hline 1 & 0.010 & 1.00 & 0.010 & 1.00 & $3.81 \cdot 10^{5}$ & 16 \\
\hline 2 & 0.100 & 1.00 & 0.100 & 1.00 & $5.23 \cdot 10^{5}$ & 19 \\
\hline 3 & 0.100 & 0.60 & 0.100 & 0.60 & $5.08 \cdot 10^{5}$ & 21 \\
\hline 4 & 0.100 & 1.40 & 0.100 & 1.40 & $6.05 \cdot 10^{6}$ & 15 \\
\hline 5 & 0.100 & 1.40 & 0.010 & 1.40 & $7.64 \cdot 10^{5}$ & 18 \\
\hline 6 & 0.055 & 1.00 & 0.051 & 0.60 & $1.94 \cdot 10^{6}$ & 17 \\
\hline 7 & 0.055 & 0.60 & 0.010 & 0.60 & $1.27 \cdot 10^{6}$ & 20 \\
\hline 8 & 0.100 & 1.00 & 0.051 & 1.00 & $9.09 \cdot 10^{6}$ & 15 \\
\hline 9 & 0.010 & 0.60 & 0.051 & 1.00 & $1.83 \cdot 10^{5}$ & 24 \\
\hline 10 & 0.010 & 1.00 & 0.051 & 1.00 & $8.27 \cdot 10^{4}$ & 24 \\
\hline 11 & 0.055 & 1.00 & 0.051 & 1.00 & $2.35 \cdot 10^{6}$ & 18 \\
\hline 12 & 0.100 & 1.40 & 0.100 & 0.60 & $1.19 \cdot 10^{7}$ & 12 \\
\hline 13 & 0.055 & 1.40 & 0.010 & 0.60 & $1.51 \cdot 10^{6}$ & 20 \\
\hline 14 & 0.055 & 1.40 & 0.051 & 1.00 & $4.22 \cdot 10^{6}$ & 19 \\
\hline 15 & 0.010 & 1.00 & 0.051 & 1.40 & $4.93 \cdot 10^{5}$ & 19 \\
\hline 16 & 0.055 & 0.60 & 0.010 & 0.60 & $1.49 \cdot 10^{6}$ & 19 \\
\hline 17 & 0.010 & 1.40 & 0.100 & 0.60 & $4.13 \cdot 10^{5}$ & 19 \\
\hline 18 & 0.010 & 0.60 & 0.100 & 1.40 & $4.19 \cdot 10^{5}$ & 20 \\
\hline 19 & 0.055 & 1.00 & 0.051 & 1.00 & $6.83 \cdot 10^{5}$ & 19 \\
\hline 20 & 0.055 & 1.00 & 0.051 & 1.00 & $1.28 \cdot 10^{6}$ & 21 \\
\hline 21 & 0.010 & 0.60 & 0.001 & 1.40 & $2.05 \cdot 10^{6}$ & 16 \\
\hline 22 & 0.100 & 0.60 & 0.100 & 1.40 & $8.18 \cdot 10^{5}$ & 18 \\
\hline 23 & 0.100 & 1.00 & 0.010 & 1.00 & $4.46 \cdot 10^{6}$ & 18 \\
\hline 24 & 0.055 & 1.00 & 0.100 & 1.00 & $1.47 \cdot 10^{6}$ & 19 \\
\hline 25 & 0.100 & 0.60 & 0.100 & 0.60 & $2.15 \cdot 10^{6}$ & 18 \\
\hline 26 & 0.010 & 1.40 & 0.100 & 1.40 & $9.39 \cdot 10^{5}$ & 21 \\
\hline 27 & 0.010 & 1.40 & 0.010 & 1.40 & $5.77 \cdot 10^{5}$ & 21 \\
\hline
\end{tabular}

reaction of $\mathrm{CBZ}$ was $\mathrm{NaOH}$ solution which was used to be on-line merged with the sample zone. The $\mathrm{NaOH}$ concentration (standard/sample carrier) and the photoreactor flow rate were optimized.

\subsection{Optimization of FIA System and Flow Conditions}

Several solvents (such as water, ethanol, acid and basic buffers and mixtures of them) were tested as eluents to achieve complete release of the analyte from the minicolumn. Weak fluorescence signals (evaluated as peak area) were obtained when water, ethanol, alkaline buffers, or mixtures of them were employed. 
However, adequate elution was achieved when an $\mathrm{HCl}$ solution was employed. Therefore, its concentration and flow rate were optimized through multivariate experimental design. Furthermore, considering the results of some earlier works [14], the influence of the elution flow direction on the sensitivity and peak shape was studied. The best results were obtained when the elution was performed in a countercurrent manner (see Figure 2).

\subsection{Experimental Design for CBZ Determination}

Factorial designs are models that allow the size of an experiment being reduced by obtaining critical information about the effects of controllable factors on a response of interest (i.e., sensitivity and sampling frequency). In this research, the chosen design was the two-level factorial, which consists of $2^{(k)}$ experiments, where $\mathrm{k}$ is the number of factors under study. Based on preliminary studies and experiments, four factors were considered including: $\mathrm{NaOH}$ concentration, $\mathrm{mol} \cdot \mathrm{L}^{-1}$ (standard/sample carrier concentration, factor A); photoreactor flow rate, $\mathrm{mL} \cdot \mathrm{min}^{-1}$ (factor $\mathrm{B}$ ); $\mathrm{HCl}$ concentration, $\mathrm{mol} \cdot \mathrm{L}^{-1}$ (eluent concentration, factor C); eluent flow rate, $\mathrm{mL} \cdot \mathrm{min}^{-1}$ (factor $\left.\mathrm{D}\right)$ (Table 1 ). In order to reduce the effect of uncontrolled variables, the experiment runs were performed in a random manner.

The evaluation consisted of the analysis of stock standard solutions of CBZ in ways to miming the analytical sample concentrations, and in all cited conditions. ANOVA tests (data not shown) were applied to experimental data in order to establish the significance of the factors studied $(p<0.05)$ upon the analytical responses. In order to get deeper insights, percentage normal probability plots for analyzed responses were built (Figure 3). Results indicated that all factors studied influenced significantly upon the two responses, but with different signs; i.e., Factors A and D, had positive effects on sensitivity; while B and C had negative. On the other hand, B, C and D effects had positive effects on sampling frequency whilst $\mathrm{A}$ had negative. Those observations were consistent with qualitative observations of the experimental setup, and with previous experiments within the studied experimental domain.

Once the level for main factors was determined, a central composite design was built, in which each design variable was assayed in the following ranges: $\mathrm{NaOH}$ concentration $0.01-0.1 \mathrm{~mol} \cdot \mathrm{L}^{-1}$; Photoreactor flow rate $0.6-1.4$ $\mathrm{mL} \cdot \mathrm{min}^{-1} ; \mathrm{HCl}$ concentration, $0.01-0.1 \mathrm{~mol} \cdot \mathrm{L}^{-1}$; eluent flow-rate, $0.6-1.4$ $\mathrm{mL} \cdot \mathrm{min}^{-1}$. Polynomial models were used to fit the responses for all the 27 experiments (see Table 2). The model coefficients were calculated by multiple regressions and validated by the analysis of variance (ANOVA). In all cases, irrelevant terms were eliminated (alpha $>0.1$ ), although some of them were maintained to ensure hierarchy. The optimization procedure was thus carried out and response surfaces were obtained. The CCD models yield polynomial equations in which the model terms are preceded by the adjusted coefficients, including the intercept. As can be observed the lack of fit was not significant $(p<0.05)$. 




Figure 3. Normal Plots for the independent variables included in the FFD.

The responses in terms of studied factors effects were obtained (Equations (4) and (5)):

$$
\begin{aligned}
S= & 1.96 \mathrm{E} 6+2.19 \mathrm{E} 8 \mathrm{NaOH} \text { conc }-8.31 \mathrm{E} 6 \text { Photoreactor FR } \\
& -4.22 \mathrm{E} 7 \mathrm{HClconc}+9.27 \mathrm{E} 6 \mathrm{Eluent} \mathrm{FR} \\
& -1.32 \mathrm{E} 8 \mathrm{NaOHconc} \text { Photoreactor FR } \\
& +7.12 \mathrm{E} 7 \mathrm{NaOH} \text { conc } \mathrm{HCl} \text { conc } \\
& -3.14 \mathrm{E} 8 \mathrm{NaOH} \text { conc Eluent FR } \\
& +2.36 \mathrm{E} 7 \mathrm{Photoreactor} \mathrm{FR} \mathrm{HCl} \text { conc } \\
& -9.82 \mathrm{E} 6 \text { Photoreactor FR Eluent FR } \\
& +1.05 \mathrm{E} 6 \mathrm{HCl} \text { conc Eluent FR } \\
& +1.88 \mathrm{E} 9 \mathrm{NaOH} \text { conc }^{2}+6.01 \mathrm{E} 6 \text { Photoreactor } \mathrm{FR}^{2} \\
& +7.37 \mathrm{E} 7 \mathrm{HCl} \text { conc }{ }^{2}+2.03 \mathrm{E} 6 \text { EluentFR } \\
& +2.25 \mathrm{E} 8 \mathrm{NaOH} \text { conc Photoreactor FR Eluent FR } \\
& -1.56 \mathrm{E} 9 \mathrm{NaOH} \text { conc }{ }^{2} \text { Photoreactor FR } \\
& -6.17 \mathrm{E} 8 \mathrm{NaOH} \mathrm{conc}{ }^{2} \mathrm{HCl} \text { conc } \\
f & =12.07-30.20 \mathrm{NaOH}^{2} \text { conc }+3.94 \text { Photoreactor FR } \\
& +9.32 \mathrm{HCl} \text { conc }+3.93 \text { Eluent FR }
\end{aligned}
$$

Desirability Function (DF) is one of the most popular chemometrics tools used to find the experimental conditions to reach simultaneously the optimal value for all the evaluated factors [18]. Figure 4 shows the DF for each individual factor under study, while maintaining the others at their optimal values. The experimental conditions corresponding to one maximum $(\mathrm{DF}=0.707) ;[\mathrm{NaOH}]$ $=0.01 \mathrm{~mol} \cdot \mathrm{L}^{-1}$; Photoreactor $\mathrm{FR}=0.6 \mathrm{~mL} \cdot \mathrm{min}^{-1} ;[\mathrm{HCl}]=0.03 \mathrm{~mol} \cdot \mathrm{L}^{-1}$ and $\mathrm{EFR}=$ $1.4 \mathrm{~mL} \cdot \mathrm{min}^{-1}$. These conditions were determined through simplex optimization using design points as starting conditions. Twenty-nine solutions were suggested, predicting values between 19 and 20 samples $\cdot \mathrm{h}^{-1}$ for sampling frequency, and $1.4 \times 10^{6}-6.1 \times 10^{6} \mathrm{cps} \cdot \mathrm{L} \cdot \mathrm{mol}^{-1}$ for sensitivity. 


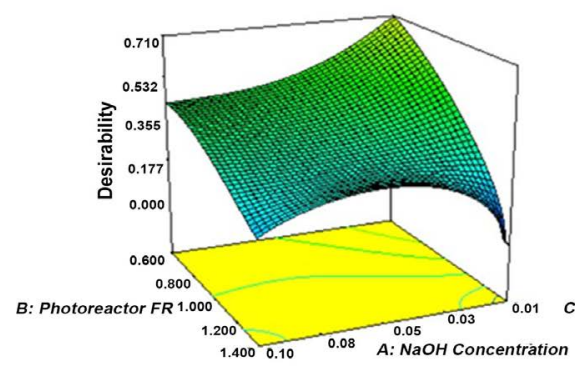

(a)

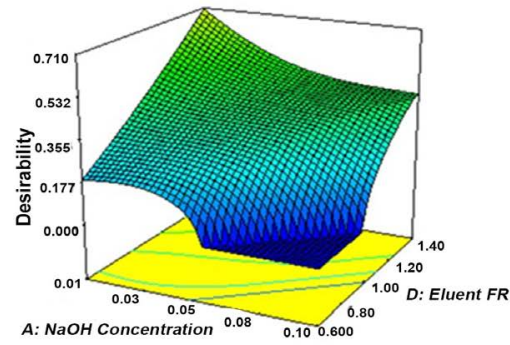

(c)

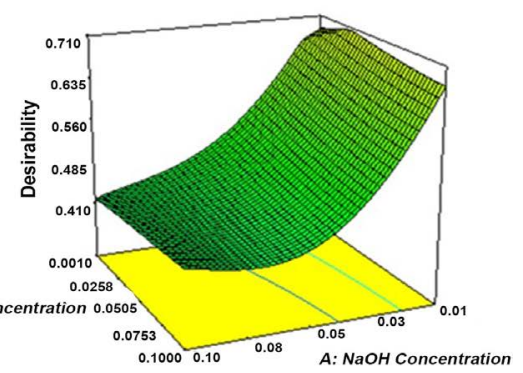

(b)

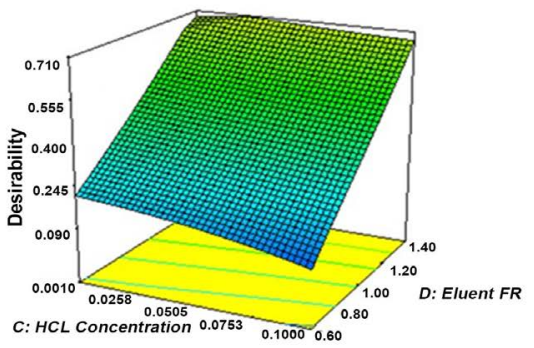

Figure 4. Response surface plots for the Desirability function in terms of (a) $\mathrm{NaOH}$ concentration and photoreactor flow rate; (b) $\mathrm{NaOH}$ and $\mathrm{HCl}$ concentrations (c) $\mathrm{NaOH}$ concentration and eluent flow rate (d) $\mathrm{HCl}$ concentration and eluent flow rate. Desirability function is showed in the four plots (a) (b) (c) and (d) in terms of two variables while the remaining were left at their optimal values; i.e. (a): $\mathrm{NaOH}$ concentration $=0.01$; (b): Photoreactor FR = 0.6; (c): $\mathrm{HCl}$ Concentration = 0.03; and (d): Eluent FR = 1.4.

\subsection{Analytical Figures of Merit}

Figure 5 shows a flow diagram obtained for the injection of standard solutions of CBZ in the optimized conditions, showing transient signals with minimum dispersion. The triplicate signals put in evidence good repeatability. The equation for the calibration graph was obtained by the least-squares regression analysis, employing the areas of the analyte standard fluorescent signals: $F=19.138 c+$ 20.982 where $F$ is the relative fluorescence intensity and $c$ the concentration of $\mathrm{CBZ}$. The method was linear in the range $0.13-40 \mu \mathrm{g} \cdot \mathrm{mL}^{-1} \mathrm{CBZ}$. The correlation coefficient was 0.9956 . The detection $\left(0.04 \mu \mathrm{g} \cdot \mathrm{mL}^{-1}\right)$ and quantification limits $\left(0.13 \mu \mathrm{g} \cdot \mathrm{mL}^{-1}\right)$ were calculated from the residual standard deviation for the calibration curve and its slope [21]. The main advantages of the proposed method are its ease of sampling, which enables a throughput of 20 samples per hour achieving analytical characteristics comparable with other available methodologies. In contrast, the present method does not require prohibitive apparatus price nor pretreatment samples involve tedious time-consuming steps. Additionally, it shows a low consumption of reagents and the samples generating a low volume of waste. Therefore, the methodology represents an eco-friendly alternative without using toxic additives.

\subsection{Application to Real Samples and Validation}

The developed on-line photoinduced fluorescence approach was applied to determinate $\mathrm{CBZ}$ concentration in tablets and syrup. 


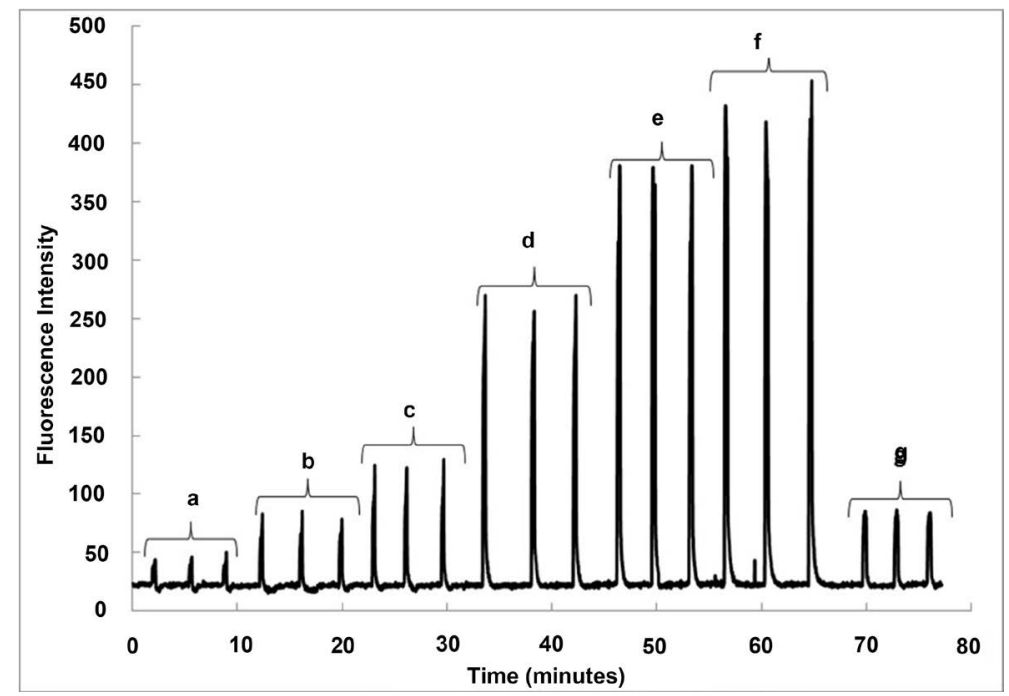

Figure 5. Transient signal (FIAgram) obtained under optimized conditions. Standard solutions of CBZ $\left(\mu \mathrm{g} \cdot \mathrm{mL}^{-1}\right)=$ (a) 0.1 ; (b) 0.5; (c) 1.0; (d) 2.0; (e) 4.0; (f); 5.0; (g) real sample of CBZ syrup without standard solution addition. $\lambda_{\mathrm{ex}}=251$ $\mathrm{nm}$ and $\lambda_{\mathrm{em}}=434 \mathrm{~nm}$; slits $=3 / 3 \mathrm{~nm}$.

In order to study the accuracy, recovery studies were carried out by the standard addition method. Known amounts of analyte were added on sample solutions of different commercial formulations. Results showed quantitative recoveries for all real samples (Table 3), indicating good accuracy of the proposed procedure. The intra-day precision of the method, based on repeatability, were determined by replicating injections $(n=6)$ of the sample solutions prepared by the standard addition method. A relative standard deviation (RSD) $<4.36 \%$ was obtained in all cases. The method was also validated against the USP HPLC official method [22]; Table 4 shows the results of the CBZ determination in pharmaceuticals by the developed spectrofluorimetric method and HPLC official methods. All values were in good statistical agreement with the nominal values, indicating good tolerance to common excipients. In comparison with the methodology proposed, the official method (USP) describes an HPLC method involving hight-cost instrument, using organic solvents, and is laborious and time-consuming. The proposed method is simple, sensitive and offers higher throug put sample than the official method. In addition, it requires small amounts of samples and reagents, so it is safe and environmentally friendly.

\section{Conclusion}

An on-line photoinduced fluorescence method for CBZ determination in pharmaceuticals coupled to multivariate calibration has been developed and validated. In alkaline aqueous medium, photo-degradation of $\mathrm{CBZ}$ is rapid and leads to the formation of a fluorescent photoproduct. The automation of the methodology was achieved by employing a very simple scheme of flow injection analysis, obtaining a sample throughput of 20 samples per hour (considering the required time for CBZ photoreaction). A proposed strategy was optimized in this 
Table 3. Determination of CBZ in pharmaceutical samples by the developed method.

\begin{tabular}{ccccc}
\hline Sample & $\begin{array}{c}\text { CBZ added } \\
\left(\mu \mathrm{g} \cdot \mathrm{mL}^{-1}\right)\end{array}$ & $\begin{array}{c}\text { CBZ found } \\
\left(\mu \mathrm{g} \cdot \mathrm{mL}^{-1}\right)\end{array}$ & Recovery ${ }^{\mathrm{b}}(\%)$ & \% RSD Intraday \\
\hline Tegretol & --- & 0.483 & --- & 4.36 \\
tablets $^{\infty}$ & 0.5 & 1.044 & 112.20 & 3.18 \\
& 1 & 1.453 & 96.95 & 1.07 \\
Tegretol & --- & 1.096 & --- & 0.85 \\
syrup $^{\infty}$ & 0.5 & 1.544 & 89.45 & 2.96 \\
\hline
\end{tabular}

${ }^{a}$ Mean value, $n=6 .{ }^{\mathrm{b}}$ Recovery $=[($ found-base $) /$ added $] \times 100$. RSD: Relative standard deviation.

Table 4. Analysis of CBZ in pharmaceutical samples by the developed spectrofluorimetric method and HPLC official methods.

\begin{tabular}{cccccc}
\hline $\begin{array}{c}\text { Sample } \\
\text { Tegretol }\end{array}$ & CBZ nominal quantity & CBZ found & E $^{\mathrm{c}}(\%)$ & CBZ found $^{\mathrm{b}}$ & $\mathrm{E}^{\mathrm{c}}(\%)$ \\
\hline Tablets & $200 \mathrm{mg}$ & $193.40 \mathrm{mg}$ & 3.30 & $201.63 \mathrm{mg}$ & 0.82 \\
Syrup & $2 \mathrm{~g} / 100 \mathrm{~mL}$ & $2.17 \mathrm{~g} / 100 \mathrm{~mL}$ & 8.50 & $2.19 \mathrm{~g} / 100 \mathrm{~mL}$ & 9.50 \\
\hline
\end{tabular}

${ }^{a}$ Spectrofluorimetric method developed in this work. ${ }^{b}$ USP official method using HPLC. 'Percent relative error (calculated considering that the tablets contain the amount reported by the manufacturing laboratories).

study using the response surface methods. This method advantages other available as it is fast, economical and produces little waste.

\section{Acknowledgements}

Authors gratefully acknowledge at Instituto de Química de San Luis- Consejo Nacional de Investigaciones Científicas y Tecnológicas (INQUISAL-CONICET, Project PIP-CONICET: 11220130100605 C0) and Universidad Nacional de San Luis (Project 22/Q228) for financial support.

\section{Conflicts of Interest}

The authors declare no conflicts of interest regarding the publication of this paper.

\section{References}

[1] Merck \& Co. (2006) Merck Index, an Encyclopedia of Chemicals, Drugs, and Biologicals. 14th Edition, Merck, Whitehouse Station.

[2] Levy, R.H., Mattson, R.H., Meldrum, B.S. and Berucca, E. (2002) Carbamazepine LP. Clinical Efficacy and Use in Epilepsy. Antiepileptic Drugs, 5th Edition.

[3] Goodman, A.G., Hardman, J.G. and Limbrid, L.E. (2001) Goodman and Gilman's the Pharmacological Basis of Therapeutics. 10th Edition, McGraw Hill, New York.

[4] Maiti, R., Mishra, B.R., Sanyal, S., Mohapatra, D., Parida, S. and Mishra, A. (2017) Effect of Carbamazepine and Oxcarbazepine on Serum Neuron-Specific Enolase in Focal Seizures: A Randomized Controlled Trial. Epilepsy Research, 138, 5-10. https://doi.org/10.1016/j.eplepsyres.2017.10.003

[5] Ghoraba, Z., Aibaghi, B. and Soleymanpour, A. (2017) Application of Cation-Modified Sulfur Nanoparticles as an Efficient Sorbent for Separation and Preconcentration of 
Carbamazepine in Biological and Pharmaceutical Samples Prior to Its Determination by High-Performance Liquid Chromatography. Journal of Chromatography $B$, 1063, 245-252. https://doi.org/10.1016/j.jchromb.2017.07.048

[6] Frag, E.Y.Z., Zayed, M.A., Omar, M.M., Elashery, S.E.A. and Mohamed, G.G. (2012) Spectrophotometric Determination of Carbamazepine and Mosapride Citrate in Pure and in Pharmaceutical Preparations. Arabian Journal of Chemistry, 5, 375-382. https://doi.org/10.1016/j.arabjc.2011.02.023

[7] Taibon, J., Schmid, R., Lucha, S., Pongratz, S., Tarasov, K., Seger, C., Timm, C., Thiele, R., Mark Herlan, J. and Kobol, U. (2017) An LC-MS/MS Based Candidate Reference Method for the Quantification of Carbamazepine in Human Serum. Clinica Chimica Acta, 472, 35-40. https://doi.org/10.1016/j.cca.2017.07.013

[8] Datar, P.A. (2015) Quantitative Bioanalytical and Analytical Method Development of Dibenzazepine Derivative, Carbamazepine: A Review. Journal of Pharmaceutical Analysis, 5, 213-222. https://doi.org/10.1016/j.jpha.2015.02.005

[9] Lozano, V.A. and Escandar, G.M. (2013) Second-Order Advantage with Excitation-Emission Photoinduced Fluorimetry for the Determination of the Antiepileptic carbamazepine in Environmental Waters. Analytica Chimica Acta, 782, 37-45. https://doi.org/10.1016/j.aca.2013.04.020

[10] Escandar, G.M., González Gómez, D., Espinosa Mansilla, A., Muñoz de la Peña, A. and Goicoechea, H.C. (2004) Determination of Carbamazepine in Serum and Pharmaceutical Preparations Using Immobilization on a Nylon Support and Fluorescence Detection. Analytica Chimica Acta, 506, 161-170. https://doi.org/10.1016/j.aca.2003.11.014

[11] Zhang, Z.-Q., Liang, G.-X., Ma, J., Lei, Y. and Lu, Y.-M. (2006) A Sensitive Flow Injection Fluorimetry for the Determination of Carbamazepine in Human Plasma. Analytical Letters, 39, 2417-2428. https://doi.org/10.1080/00032710600822866

[12] Walash, M.I., El-Enany, N. and Askar, H. (2015) Validated Spectrofluorimetric Method for the Determination of Carbamazepine in Pharmaceutical Dosage Forms after Reaction with 4-chloro-7-nitrobenzo-2-oxa-1,3-diazole (NBD-Cl). Luminescence, 30, 1119-1124. https://doi.org/10.1002/bio.2868

[13] Hurtado-Sánchez, M.C., Lozano, V.A., Rodríguez Cáceres, M.I., Durán-Merás, I. and Escandar, G.M. (2015) Green Analytical Determination of Emerging Pollutants in Environmental Waters Using Excitation-Emission Photo Induced Fluorescence Data and Multivariate Calibration. Talanta, 134, 215-223.

https://doi.org/10.1016/j.talanta.2014.11.022

[14] Peralta, C.M., Henestrosa, C., Gil, R.A., Fernández, L.P. and Acosta, G. (2017) Novel Spectrofluorimetric Method for Boldine Alkaloid Determination in Herbal Drugs and Phytopharmaceuticals. Spectrochimica Acta Part A, 184, 101-108. https://doi.org/10.1016/j.saa.2017.04.039

[15] amini, Y., Faraji, M., Shariati, S., Hassani, R. and Ghambarian, M. (2008) On-Line Metals Preconcentration and Simultaneous Determination Using Cloud Point Extraction and Inductively Coupled Plasma Optical Emission Spectrometry in Water Simples. Analytica Chimica Acta, 612, 144-151.

https://doi.org/10.1016/j.aca.2008.02.034

[16] Bezerra, M.A., Santelli, R.E., Oliveira, E.P., Villar, L.S. and Escaleira, L.A. (2008) Response Surface Methodology (RSM) as a Tool for Optimization in Analytical Chemistry. Talanta, 76, 965-977. https://doi.org/10.1016/j.talanta.2008.05.019

[17] Martins, A.C., Bukman, L., Vargas, A.M.M., Barizão, É.O., Moraes, J.C.G., Visentainer, J.V. and Almeida, V.C. (2013) The Antioxidant Activity of Teas Measured by 
the FRAP Method Adapted to the FIA System: Optimising the Conditions Using the Response Surface Methodology. Food Chemistry, 138, 574-580.

https://doi.org/10.1016/j.foodchem.2012.10.143

[18] E-Handbook of Statistical Methods. http://www.itl.nist.gov/div898/handbook

[19] Acosta, G., Silva, R., Gil, R.A., Gómez, R. and Fernández, L.P. (2013) On-Line Enantioseparation of Chlorpheniramine Using $\beta$-Cyclodextrin and Carbon Nanotubes after Multivariate Optimization. Talanta, 105, 167-172.

https://doi.org/10.1016/j.talanta.2012.11.045

[20] Pan, Y., Cheng, S.S., Yang, X., Ren, J., Fang, J., Shang, C., Song, W., Lian, L. and Zhang, X. (2017) UV/Chlorine Treatment of Carbamazepine: Transformation Products and Their Formation Kinetics. Water Research, 116, 254-265. https://doi.org/10.1016/j.watres.2017.03.033

[21] Currie, L.A. (1999) Detection and Quantification Limits: Origins and Historical Overview. Analytica Chimica Acta, 391, 127-134. https://doi.org/10.1016/S0003-2670(99)00105-1

[22] USP 34-NF 29 (2011) United States Pharmacopea and National Formulary, United States Pharmacopeial Convention. 